\title{
Detection and Molecular Characterization of Avian Infectious Laryngotracheitis Virus Isolated from a Breeder Flock
}

\author{
S. Jaisree ${ }^{1 *}$, K. Shoba ${ }^{1,2}$, A. Ramesh ${ }^{3}$, K. Vijayarani ${ }^{4}$, S. Vairamuthu ${ }^{5}$ and R. Bharathi ${ }^{1}$ \\ ${ }^{1}$ Central University Laboratory, Centre for Animal Health Studies, Tamil Nadu Veterinary and Animal Sciences University, \\ Madhavaram Milk Colony, Chennai, Tamil Nadu, INDIA \\ ${ }^{2}$ Department of Veterinary Microbiology, Madras Veterinary College, Tamil Nadu Veterinary and Animal Sciences University, \\ Vepery, Chennai, Tamil Nadu, INDIA \\ ${ }^{3}$ Vaccine Research Centre - Viral Vaccine, Centre for Animal Health Studies, Tamil Nadu Veterinary and Animal Sciences \\ University, Madhavaram Milk Colony, Chennai, Tamil Nadu, INDIA \\ ${ }^{4}$ Department of Bioinformatics and ARIS cell, Madras Veterinary College, Tamil Nadu Veterinary and Animal Sciences \\ University, Vepery, Chennai, Tamil Nadu, INDIA \\ ${ }^{5}$ Centralised Clinical Laboratory, Madras Veterinary College, Tamil Nadu Veterinary and Animal Sciences University, Vepery, \\ Chennai, Tamil Nadu, INDIA \\ *Corresponding author: S Jaisree; E-mail: jaisree.s@tanuvas.ac.in
}

Received: 04 Feb., 2021

Revised: 15 April, 2021

Accepted: 22 April, 2021

\begin{abstract}
Infectious laryngotracheitis (ILT) is an economically important viral respiratory disease in poultry. Recently, re-emergence of Infectious laryngotracheitis virus (ILTV) has been reported in several countries. This study reports the severe form of ILTV outbreak in a breeder flock located at Chittoor district of Andhra Pradesh. Morbidity and mortality rate observed in the current outbreak were $70 \%$ and $12 \%$ respectively. On post mortem examination haemorrhage and caseous plug were noticed in the trachea. PCR for ICP4 gene was targeted for initial screening and ILTV was isolated from positive samples. Molecular characterization was carried out by $g J$ gene sequencing, one of the virulent gene responsible for viral egress. Phylogenetic analysis revealed that the study isolate is genetically related to Australian virulent virus, Italy virulent virus, Russian virulent virus, USA virulent virus and CEO vaccines.
\end{abstract}

\section{HIGHLIGHTS}

(0 This paper reports the outbreak of avian infectious laryngotracheitis in a breeder flock at Chittoor.

(0 Diagnosis was carried out targeting ICP4 gene of ILTV and molecular characterization was carried out with $g J$ gene.

( Phylogenetic analysis revealed that the study isolate was related to Australian virulent virus, Italy virulent virus, etc.

Keywords: Infectious Laryngotracheitis, PCR, ICP4 gene, phylogenetic analysis, gJ gene

Poultry farming in India has attained tremendous growth from backyard flock to an organized sector during the past six decades which contributes to $0.66 \%$ of India's GDP (Prabaharan, 2014). The intensive poultry farming practices makes them more susceptible to infectious disease which poses threat to the supply of safe and quality protein. Infectious laryngotracheitis (ILT) is one of the important infectious disease of chicken which causes greater economic loss during outbreaks. Infectious laryngotracheitis is caused by Gallidherpesvirus I (GaHV1), a double stranded DNA virus of $150 \mathrm{~kb}$ in size belongs to the genus Iltovirus, family Herpesviridae, subfamily Alphaherpesvirinae. In addition to chicken, ILTV can also

How to cite this article: Jaisree, S., Shoba, K., Ramesh, A., Vijayarani, K., Vairamuthu, S. and Bharathi, R. (2021). Detection and molecular characterization of Avian infectious laryngotracheitis virus isolated from a breeder flock. J. Anim. Res., 11(2): 257-262. Source of Support: None; Conflict of Interest: None क्ष 
affects pheasants, partridges and peafowl. ILTV causes high morbidity of $90-100 \%$ and mortality of $5-70 \%$. Economic loss is mainly due to reduced growth rate, decrease in production and mortality (Bhutia and Singh, 2017; OIE, 2018).

Infectious laryngotracheitis virus was first reported in Canada in 1925 and now it is prevalent worldwide (Cover, 1993). ILTV in India was first reported in 1964 and later reported by several authors (Singh et al., 1964). Recently, re-emergence of Infectious laryngotracheitis has been reported and is in increasing trend (Gowthaman et al., 2016). The present study aims to report the ILT outbreak in a breeder flock located at Chittoor district. Molecular characterization of ILTV is being carried out in different countries for detecting circulating ILTV. The genes targeted for differentiation of ILTV strains in earlier studies were $g G, g B, I C P 4, O R F A / B$ and $T K$ (Menendez et al., 2014). Recently, it was reported that the field strains and vaccine strains were better differentiated with the $\mathrm{gJ}$ gene sequences than $g B$ and ICP4 sequences in Argentina and also observed that the $g J$ sequence was the most informative segment for strain differentiation (Craig et al., 2017). Hence, $g J$ gene was explored for the molecular characterization.

\section{MATERIALS AND METHODS}

\section{Case history}

A breeder flock in Chittoor district of Andhra Pradesh reported with gasping and mortality in birds. The flock consisted of 1380 roosters and 11,565 hens of COBB $430 \mathrm{Y}$ strain of 36 weeks old. The signs observed in affected birds were gasping, difficulty in respiration with extension of neck (pump handle respiration) (Fig. 1), nasal discharge and rales. Both roosters and hens were affected and there was no sex difference. Morbidity and mortality rates observed in this current outbreak were $70 \%$ and $12 \%$ respectively. Post mortem examination was carried out which revealed haemorrhage in trachea and caseous plug in larynx and trachea (Fig. 2). Lesions were noticed only in larynx and trachea. No lesions were observed in other organs.

Heart blood swabs, tracheal swabs and tracheas were collected from dead birds (5 Nos.) for bacterial and viral examination. Heart blood swabs were inoculated into blood agar, brain heart infusion agar, nutrient agar and MacConkey agar plates.



Fig. 1: Birds affected with ILTV showing pump handle respiration

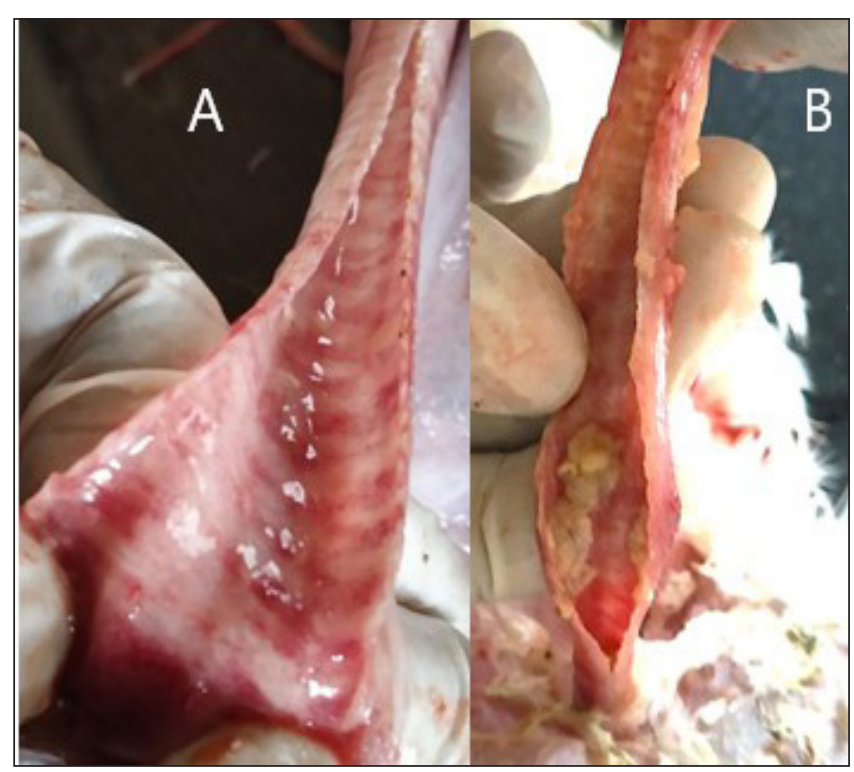

Fig. 2: Birds affected with ILTV showing haemorrhagic tracheitis and caseous plug in larynx. (A) Haemorrhage in trachea; (B) Caseous plug in larynx

Plates were incubated at $37^{\circ} \mathrm{C}$. To rule out the involvement of Mycoplasma sp. tracheal swabs were inoculated into PPLO broth and incubated in a $\mathrm{CO}_{2}$ incubator at $37^{\circ} \mathrm{C}$ for 7 days. 


\section{Polymerase chain reaction (PCR)}

Total genomic DNA was extracted from tracheal samples by phenol -chloroform extraction method. PCR for ICP4 gene was performed for rapid diagnosis (OIE, 2018). Briefly, PCR condition was carried out in $25 \mu \mathrm{l}$ volume consisting of $12.50 \mu \mathrm{l}$ of $2 \mathrm{X}$ Red dye master mix (Ampliqon), $1 \mu \mathrm{l}(10 \mathrm{pmol} / \mu \mathrm{l})$ of each primer (F:5' CTTCAGACTCCAGCTCAT CTG-3' and R-5'AGTCATGCGTCTATGGCGTTGAC-3'), $8.5 \mu$ l nuclease free water and $2 \mu \mathrm{l}$ of extracted DNA sample. The conditions for PCR reactions were as follows; initially 94 ${ }^{\circ} \mathrm{C}$-for $5 \mathrm{~min}$; followed by 35 cycles of $94{ }^{\circ} \mathrm{C}$ - for $45 \mathrm{~s}, 62$ ${ }^{\circ} \mathrm{C}$ - for $30 \mathrm{~s}$ and $72{ }^{\circ} \mathrm{C}$ for $45 \mathrm{~s}$ with final extension cycle at $72{ }^{\circ} \mathrm{C}$ for $10 \mathrm{~min}$. PCR products were electrophoresed on $1.5 \%$ agarose gel and documented with BioRad $\mathrm{XR}^{+}$gel doc imager.

\section{Virus isolation}

Tracheal suspensions $(10 \% \mathrm{w} / \mathrm{v})$ were treated with antibiotics (Streptomycin sulphate 2,000 IU/ml \& penicillin $\mathrm{G} 10,000 \mathrm{IU} / \mathrm{mL}$ ) and $0.1 \mathrm{ml}$ was inoculated into chorioallantoic membrane (CAM) of 11days old specific pathogen free (SPF) eggs, incubated in an egg incubator for seven days (OIE, 2018). Three blind passages were carried out in SPF eggs. Histopathological examination of CAM was carried out to find out the histological changes. CAM were dehydrated and embedded in paraffin. The paraffin embedded tissues were cut at $4-5 \mu$ thickness, stained with Harri's haematoxylin and eosin method.

\section{Phylogenetic analysis}

Glycoprotein $\mathrm{J}(g J)$ gene was amplified from virus isolated from SPF eggs using gJ gene specific primers (Craig et al., 2017). PCR reaction was carried out with Q5HiFi Taq DNA polymerase $\left(\mathrm{NEB}^{\circledR}\right)$ with GC enhancer. PCR mixture was kept in a PCR thermal cycler with the following conditions: $98^{\circ} \mathrm{C}-30 \mathrm{~s} ; 35$ cycles of $98^{\circ} \mathrm{C}-30 \mathrm{~s}$, $62{ }^{\circ} \mathrm{C}-45 \mathrm{~s}$ and $72{ }^{\circ} \mathrm{C}$ for $90 \mathrm{~s}$, final extension at $72{ }^{\circ} \mathrm{C}$ for 10 minutes. Bulk PCR products were purified with Biobasic $^{\circledR}$ gel extraction kit and sent for Sanger dideoxy sequencing to a commercial sequence service provider. Sequence was aligned using BioEdit ${ }^{\mathrm{TM}}$ software and aligned sequence was submitted to GenBank (Accession number - MT997150.1). phylogenetic analysis was carried out with MEGA[X] $]^{\mathrm{TM}}$ software using Tamura-Nei model, maximum likelihood method with 1000 bootstrap values (Tamura and Nei (2013); Kumar et al., 2018).

\section{RESULTS AND DISCUSSION}

Avian Infectious Laryngotracheitis is an economically important contagious viral diseases of poultry. Earlier it was believed that adult birds are highly susceptible to ILTV than young birds (Guy and Bagust, 2003). Later, it was reported that all age group of birds, breeds and strains are equally susceptible to the infection (Gowthaman et al., 2016). The age of the birds in this current outbreak was 36 weeks and they were also one of the susceptible age group to ILTV infection.

Moreover, no chicks and grower were maintained in that flock to ascertain age difference in the susceptibility to ILTV. The clinical signs viz. gasping, difficulty in respiration with extension of neck, rattling and post mortem lesions were well correlated with the signs and lesions reported earlier (Chacon and Ferreira, 2009). In severe form of ILT, the morbidity and mortality ranges from $90-100 \%$ and $5-70 \%$ respectively. Whereas, in milder form of ILTV infection, the morbidity is low up to $5 \%$ and mortality ranges from 0.5 to $2 \%$ (Bhutia and Singh, 2017). The morbidity (70\%) and mortality (12\%) observed in the present outbreak indicates severe form of infection.

PCR is the most sensitive and rapid method for the detection of ILTV (OIE, 2018). DNA extracted from all the five tracheal samples were found positive and yielded 635 bp ICP4 gene specific amplicons (Fig. 3). No bacteria of pathogenic importance could be isolated from the tracheal swabs and heart blood swabs in the current outbreak which ruled out the involvement of bacterial organisms. The clinical signs, post mortem findings in correlation with PCR findings had proven that the outbreak was due to ILTV. On isolation of ILTV in SPF eggs, characteristic pock like lesion was observed after third passage (Fig. 4). Histopathological examination of CAM showed congestion, mononuclear cell infiltration and characteristic intranuclear inclusion bodies (Figure $5 \mathrm{a}, 5 \mathrm{~b}, 5 \mathrm{c})$. These findings were in accordance with the earlier findings (OIE, 2018). 


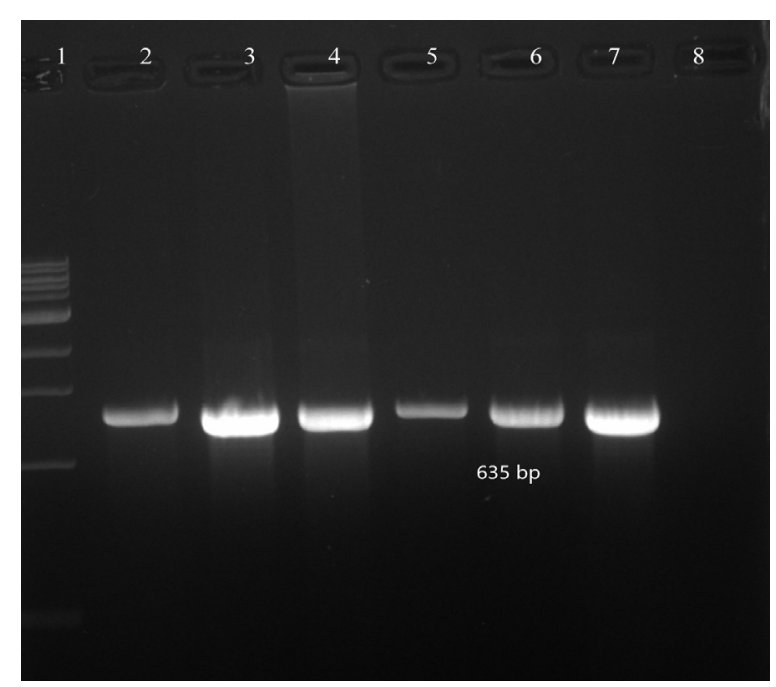

Fig. 3: PCR amplification of ICP4 gene from ILTV suspected samples- Lane 1- $1 \mathrm{~kb}$ MW marker; Lane 2 to 6 - Samples suspected for ILTV showing positive result; Lane 7 - Positive control; Lane 8 - Negative control.

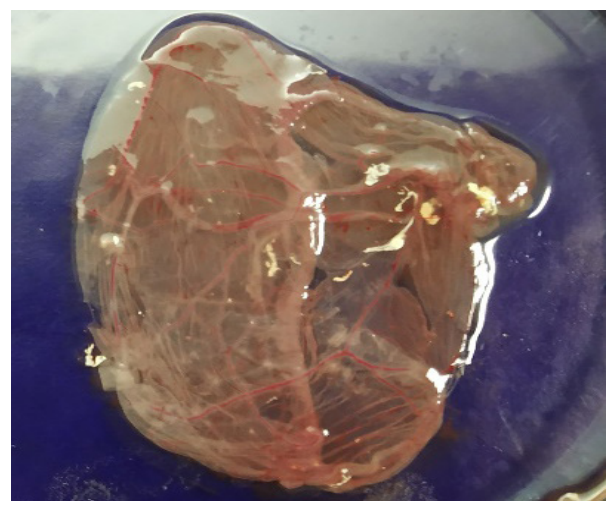

Fig. 4: Chorioallantoic membrane inoculated with ILTV positive tracheal sample by PCR showing pock lesion after $3^{\text {rd }}$ passage

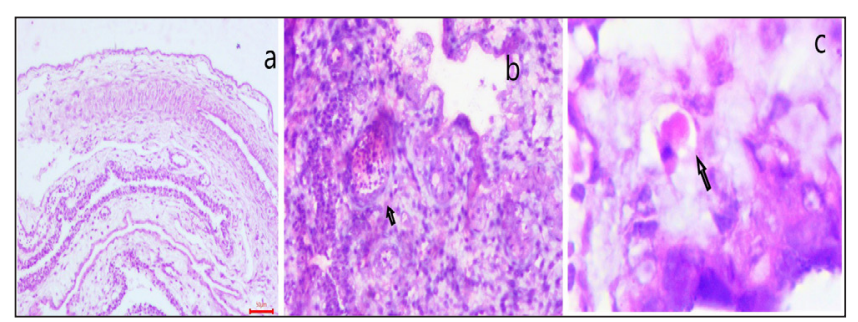

Fig. 5: Histopathology of chorioallantoic membrane (CAM) inoculated with ILTV. a. Control CAM (H\&E- 20X); b. ILTV inoculated CAM showing congestion and mononuclear cell infiltration (H\& E -20 X); c. ILTV inoculated CAM showing intranuclear inclusion (H\& E-100X)
DNA was extracted from the current isolate was used for the amplification of $g J$ gene. PCR for $g J$ gene yielded 1390 bp product (Fig. 6). ILTV isolates were classified into five haplotypes based on the nucleotide positions at 461,484,832,878 and 894 (Craig et al., 2017). The nucleotides present in the $g J$ gene sequence of current isolate in the specified positions were 461/A, 484/C, $832 / \mathrm{A}, 878 / \mathrm{T}$ and $894 / \mathrm{G}$ and belong to the haplotype II which are related to CEO (Chicken embryo origin) viruses. Phylogenetic analysis was made with 44 reference sequences from GenBank. Phylogenetic analysis clustered the sequence into three groups. Group I with TCO (Tissue culture origin) vaccine, Group II and III with CEO vaccine and virulent viruses. The study isolate was related to Australia virulent virus, Italy virulent virus, Russian virulent virus, USA virulent virus and CEO vaccines (Fig.7). The $g J$ sequence differentiated $\mathrm{CEO}$ and $\mathrm{CEO}$ related virulent strains from TCO vaccine strains. But it didn't differentiate among the virulent strain. The genes targeted to know the circulating strain varies depending upon the geographical region (Menendez et al., 2014). Earlier studies in India were based on ICP4 and TK gene sequence analysis which reported that the Indian isolates belong to CEO related strain (Gowthaman et al., 2016). In this study $g J$ gene was explored for the genetic information which revealed that the current isolate belongs to CEO related virulent strain.



Fig. 6: Amplification ILTV gJ gene for sequencing - Lane 1- 1 $\mathrm{kb}$ ladder $\left(\mathrm{NEB}^{\circledR}\right)$, Lane 2- Negative control, Lane 3- Sample 




Fig. 7: Phylogenetic tree constructed by Maximum likelihood method Tamura-Nei model with 1000 bootstrap values

Globally, ILTV is controlled using either tissue culture attenuated vaccine or chicken embryo attenuated vaccines. ILTV vaccination is not practised in India and the current outbreak might be due to virulent virus genetically related to CEO origin. ILTV vaccines prevent mortality but it doesn't prevent virulent virus infection and excretion. The spontaneous recombination event between vaccine virus and the virulent virus leads to the development of new variants which causes widespread outbreak of ILTV globally even in countries where live attenuated vaccines are used. Several authors reported that the vaccine virus and virulent virus were closely related and CEO related virulent viruses are circulating and causing the disease (Gowthaman et al., 2016; Loncoman et al., 2017; La et al., 2019) and supports our findings.

\section{CONCLUSION}

The study revealed that the outbreak in breeder flock was caused by ILT virus closely related to CEO related virulent virus. The molecular epidemiology of ILTV in India is very limited. Hence, more molecular surveillance is required in India to ascertain the circulating strain.

\section{REFERENCES}

Bhutia, L.B. and Singh, D.Y. 2017. Occurrence of Infectious Laryngotracheitis in Poultry Population of Mizoram, India. Int. J. Curr. Res., 9(06): 51706 - 51710.

Chacon, J.L. and Ferreira, A.J. 2009. Differentiation of field isolates and vaccine strains of infectious laryngotracheitis virus by DNA sequencing. Vaccine, 27: 6731 - 6738.

Cover, M.S. 1993. The early history of infectious laryngotracheitis. Avian Dis., 40(3): 494 - 500.

Craig, M.I., Rojas, M.F., Ploeg, C.A., Van Der and Olivera, V.2017. Molecular characterization and cluster analysis of Field isolates of avian infectious laryngotracheitis Virus from Argentina. Front. Vet. Sci., 4: 212.

Davison, A.J. 2010. Herpesvirus systematics. Vet. Microbiol., 143: 52 - 69.

Gowthaman, V., Koul, M. and Kumar, S. 2016. Avian infectious laryngotracheitis: A neglected poultry health threat in India. Vaccine, 34 (36): 4276 - 4277.

Guy, J.S. and Bagust, T.J. Laryngotracheitis. In: Diseases of Poultry, Eleventh Edition, Saif, Y.M., Barnes, H.J., Glisson, J.R., Fadly, A.M., McDougald, L.R. and Swayne, D.. Iowa State University Press, USA, 2003; pp. $124-134$.

Kumar, S., Stecher, G., Li, M., Knyaz, C. and Tamura, K. 2018. MEGA X: Molecular Evolutionary Genetics Analysis across computing platforms. Mol. Biol. Evol., 35: 1547-1549.

La, T.M., Choi, E.J., Lee, J.B., Park, S.Y. and Song, C.S. 2019. Comparative genome analysis of Korean field strains of infectious laryngotracheitis virus. PLoS One, 14(2): $\mathrm{e} 0211158$.

Loncoman, C.A., Hartley, C.A., Coppo, M.J.C., Vaz, P.K. and Diaz-Méndez A. 2017 Genetic diversity of infectious laryngotracheitis virus during in vivo coinfection parallels viral replication and arises from recombination hot spots within the genome. J. Appl. Environ. Microbiol., 83(23): e01532 - 17

Menendez, K.R., Garcia, M., Spatz, S., Nathaniel, L. and Menendez, K.R. 2014. Molecular epidemiology of infectious laryngotracheitis: A review. Avian Pathol., 43(2): 108 - 117.

OIE, World organization for Animal Health. Manual of Diagnostic Tests and Vaccines for Terrestrial Animals. Avian Infectious Laryngotracheitis 2018; Chapter. 3.3.3, pp. 810 820

Prabakaran, R. 2014. Indian Poultry Industry - Current Status, Practical Challenges and Opportunities. In: Proceedings of the $31^{\text {st }}$ Annual Conference and National Symposium of Indian Poultry Science Association (IPSACON 2014), Namakkal, India 2014; pp. 18-20. 
Singh, S.B., Singh, G.R. and Singh, C.M. 1964. A preliminary report on the occurrence of infectious laryngotracheitis of poultry in India. Poult Sci., 43: 492 - 4.
Tamura, K. and Nei, M. 1993. Estimation of the number of nucleotide substitutions in the control region of mitochondrial DNA in humans and chimpanzees. Mol. Biol. Evol., 10: 512526. 